\title{
Dyshormia in focal epilepsy
}

\section{Disormia em Epilepsia Focal}

Mauricio F. Villamar' ${ }^{1}$ Frank G. Gilliam ${ }^{1}$

A 37-year-old man was evaluated for recurrent episodes of impaired awareness since childhood. EEG showed right temporal focal dyshormia (Figure 1). MRI revealed a right temporal mass (Figure 2).

Niedermeyer coined the term "dyshormia" to define epileptiform discharges that occur in conjunction with K-complexes on arousal from sleep ${ }^{1}$. Although dyshormia was originally described in generalized epilepsies ${ }^{1}$, unilateral, focal dyshormia is occasionally seen in focal epilepsies².

In focal epilepsies, epileptiform discharges associated with K-complexes are typically ipsilateral to the epileptogenic zone, and are more common in frontal than in temporal lobe epilepsies ${ }^{2}$. Their presence can assist in localization of epileptogenic regions.

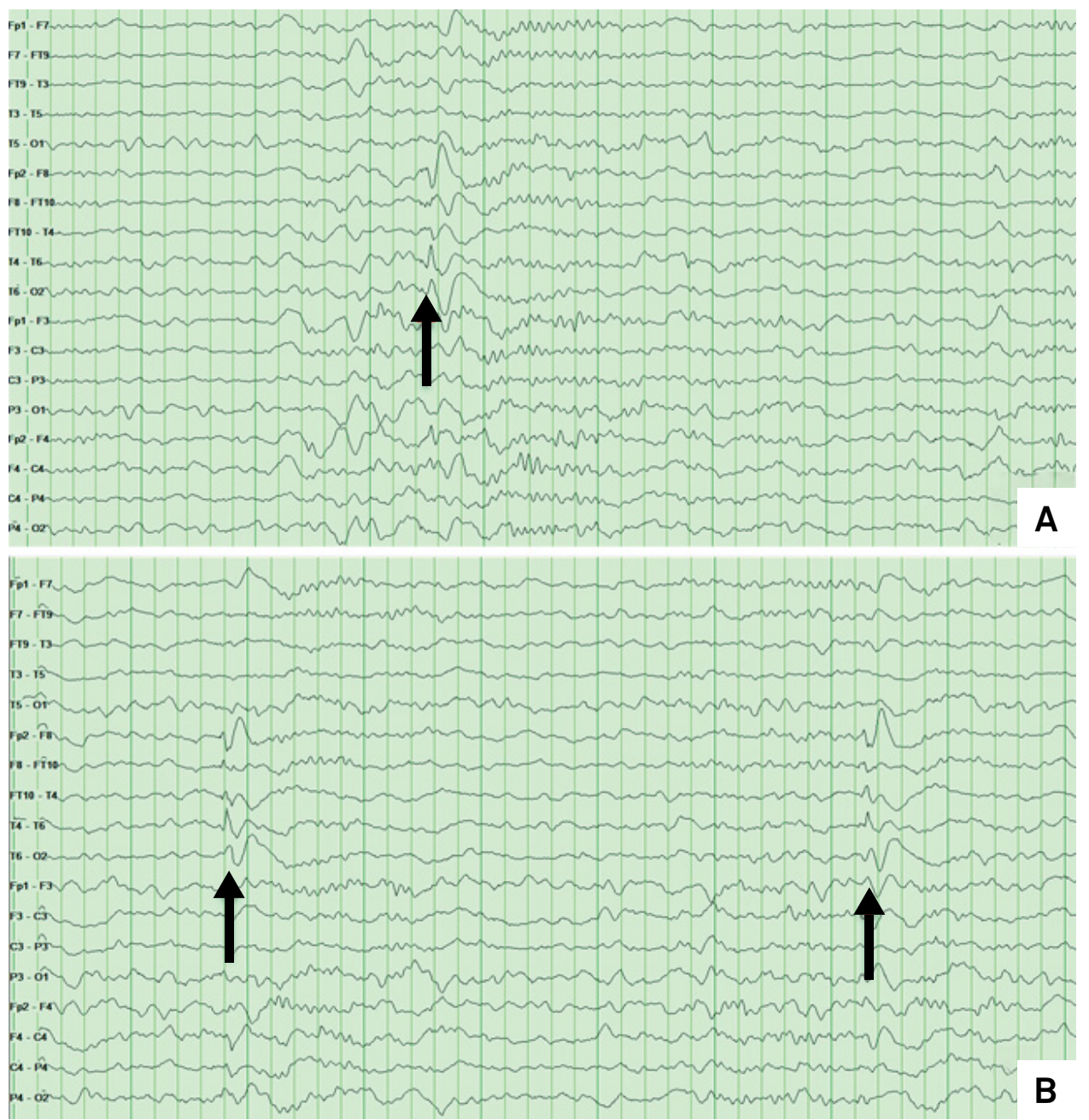

Figure 1. Electroencephalographic abnormalities in focal dyshormia. A) and B) Right temporal epileptiform K-complexes during N2 sleep (arrows).

${ }^{1}$ University of Kentucky Department of Neurology, Lexington, KY, USA.

Correspondence: Frank G. Gilliam; Department of Neurology, University of Kentucky; 740 S Limestone St.; Kentucky Clinic - J417; Lexington, KY, USA 405360298; E-mail:f.gilliam@uky.edu

Conflict of interest: There is no conflict of interest to declare.

Received 22 February 2018; Accepted 25 March 2018. 

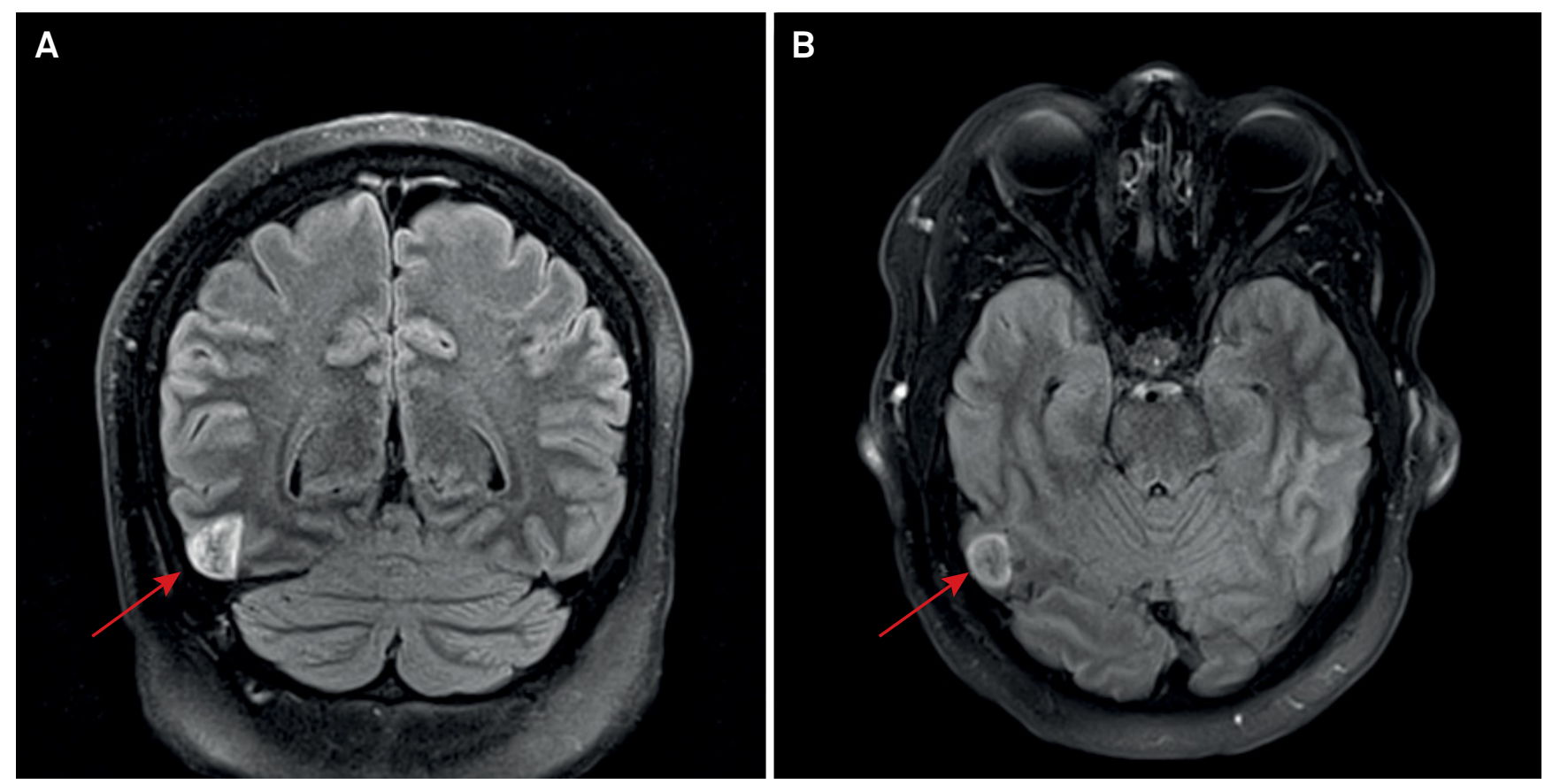

Figure 2. Neuroimaging showing a right temporal mass. A) coronal and B) axial non-contrast T2-FLAIR-weighted brain MRI shows a hyperintense right posterior temporal lobe lesion with heterogeneous internal signal (arrows). Pathology revealed a dysembryoplastic neuroepithelial tumor, WHO grade I.

\section{References}

1. Niedermeyer E. Epileptiform $\mathrm{K}$

complexes. Am J Electroneurodiagnostic

Technol. 2008 Mar;48(1):48-51.
2.

Geyer JD, Carney PR, Gilliam F. Focal epileptiform spikes in conjuction with K-complexes. J Clin Neurophysiol. 2006 Oct;23(5):436-9. https://doi.org/10.1097/01.wnp.0000228499.92313.d6 